\title{
The Zoo Task: A Novel Metacognitive Problem-Solving Task Developed with a Sample of African American Children from Schools in High Poverty Communities
}

\author{
Jwalin Patel ${ }^{1} \quad$ Amanda Aldercotte $^{1} \quad$ Maria Tsapali $^{1}$ \\ Zewelanji Serpell ${ }^{2} \quad$ Teresa Parr ${ }^{2}$ \\ Michelle R. Ellefson ${ }^{1}$ \\ ${ }^{1}$ University of Cambridge \\ ${ }^{2}$ Virginia Commonwealth University
}

Please cite this article as: Patel, J., Aldercotte, A., Tsapali, M., Serpell, Z., Parr, T., \& Ellefson, M. R. (2021). The Zoo Task: A Novel Metacognitive Problem-Solving Task Developed with a Sample of African American Children from Schools in High Poverty Communities. Psychological Assessment. https://doi.org/10.1037/pas0001033

\section{Author Notes}

This article was accepted for publication by Psychological Assessment on 15th March 2021. This is the accepted version.

CAmerican Psychological Association, 2021. This paper is not the copy of record and may not exactly replicate the authoritative document published in the APA journal. Please do not copy or cite without author's permission. The final article is available, upon publication, at:

\section{https://doi.org/10.1037/pas0001033}

Corresponding Author. Correspondence concerning this article should be addressed to Michelle R. Ellefson, University of Cambridge Faculty of Education, 184 Hills Road, Cambridge, CB2 8PQ, United Kingdom. Email: mre33@cam.ac.uk. 
Acknowledgements. The research reported here was supported by the Institute of Education Sciences, U.S. Department of Education, through Grant R305A110932 to the University of Cambridge. The opinions expressed are those of the authors and do not represent views of the Institute or the U.S. Department of Education. Special thanks to Geoff Martin for Thinking Games website programming, Aysha Foster for task instructions feedback, and Richard Parkin for proofreading. The full dataset is available at https://osf.io/gkac3, the Zoo task booklet and administration instructions licensed under a Creative Commons Attribution 4.0 International License at https://osf.io/c6aq7/, an overview of the full grant project at https://osf.io/yac8e, a preprint at https://psyarxiv.com/78y96/.

Author Contributions. Ellefson, Serpell and Parr submitted the initial grant application and study concept. Aldercotte, Ellefson and Serpell developed the task. Ellefson oversaw the development of the Thinking Games website. Data collection was supervised by Ellefson, Serpell, Aldercotte and Parr. Aldercotte, Ellefson and Tsapali completed the initial data entry and devised the coding scheme for the initial seven categories for the Zoo task for the pilot and main study. Ellefson, Serpell and Aldercotte managed and conducted the scoring, data entry, data cleaning and all other general data management for the metamemory, problem-solving and general cognitive ability tasks. Ellefson, Patel and Tsapali prepared the open science data files and task descriptions. Patel developed and implemented the coding schemes for task accuracy, metacognitive control, monitoring, and evaluation measures as well as the absolute accuracy and bias. Patel analyzed and interpreted the results here as well as for a thesis submitted as partial fulfillment of a master's degree at the University of Cambridge. Patel and Ellefson drafted the manuscript, with critical revisions from Tsapali, Serpell and Parr. All authors approved the final draft.

Further Acknowledgements. This manuscript extends the analyses conducted in Jwalin Patel's thesis, which was completed as a part of an MPhil degree program at the University of Cambridge. The thesis is archived at https://www.repository.cam.ac.uk/handle/1810/288828. 
The data presented here are the result of work by a large team from the University of Cambridge, Virginia State University, Virginia Commonwealth University and Ashley-Parr, LLC (listed alphabetically by last name): Temitope Adeoye, Mariah Adlawan, Amanda Aldercotte, Annabel Amodia-Bidakowska, Cortney Anderson, Christopher Ashe, Joseph Beach, Aaron Blount, Alexander Borodin, Lyndani Boucher, Aaron Blount, Lakendra Butler, Yufei Cai, Emma Chatzispyridou, Parul Chaudhary, Laura Clarke, Tavon Carter, Taelor Clay, Jackson Collins, Brittany Cooper, Aiden Cope, Briana Coardes, Breanna Cohen, Aiden Cope, Amenah Darab, Moneshia Davis, Shakita Davis, Asha Earle, Mary Elyiace, Nadine Forrester, Sophie Farthing, Pippa Fielding Smith, Aysha Foster, Gill Francis, Kristine Gagarin, Amed Gahelrasoul, Marleny Gaitan, Summer Gamal, Katie Gilligan, Cynthia Gino, Reinaldo Golmia Dante, Zejian Guo, Aditi Gupta, Jennifer Hacker, Shanai Hairston, Khaylynn Hart, Donita Hay, Rachel Heeds, Sonia Ille, Joy Jones, Madhu Karamsetty, Spencer Kearns, Marianne Kiffin, Hyunji Kim, Wendy Lee, Steven Mallis, Dr. Geoff Martin, Tyler Mayes, Alexandria Merritt, Roshni Modhvadia, Dedrick Muhammad, Susana Nicolau, Christian Newson, Seth Ofosu, Esther Obadare, Jwalin Patel, Chloe Pickett, Tanya Pimienta, Connor Quinn, Kelsey Richardson, Michael Randall, Fran Riga, Tennisha Riley, Natalie Robles, Leah Saulter, Kristin Self, Tiera Siedle, Julian Smith, Abi Solomon, Adam Sukonick, Amelia Swafford, Krystal Thomas, Richard Thomas, John Thompson, Tris Thrower, Jr., Quai Travis, Maria Tsapali, Jorge Vargas, Tony Volley, Christopher Walton, Elexis White, Karrie Woodlon, Zhuoer Yang, Shamika Young, Sterling Young, Cheyenne Yucelen, Anne Zonneveld. These researchers were directed by the PI/CoPIs: Drs. Michelle Ellefson, Zewelanji Serpell, and Teresa Parr. 


\begin{abstract}
Metacognition is important for monitoring and regulating cognitive processes, decisionmaking, problem-solving and learning. Despite widespread interest in metacognition, measuring metacognition in children poses a significant challenge. Some qualitative and observational metrics exist, but are restricted by scalability, range of metacognitive components measured, and use of different metrics compared with tasks for adults. We developed the Zoo Task - a novel, scalable, paper-based task that measures multiple aspects of metacognition that is less conflated by other variables like verbal ability and does not require video recording children. Children ( $N=204$, ages 7-12 years, mostly from African American backgrounds) attending schools in high poverty urban areas contributed to its development. In addition, they completed a standard metacognition of memory task similar to those already used with children and adults. The results indicate that the novel task trials are reliable and have good criterion validity. The Zoo Task could bridge the current gap between existing metrics of metacognition for children and adults.
\end{abstract}

\title{
Public Significance Statement
}

We developed a novel measure for metacognition - The Zoo Task - with a large group of children attending schools in a high poverty urban area. Metacognition thought of as the ability to understanding how to think or learn; it is vital for school success and even later employment. This Zoo Task focuses on the thinking skills used when children are solving problems.

\section{Keywords}

metacognitive memory, metacognitive problem solving, metacognitive monitoring, metacognitive control 


\section{The Zoo Task: A Novel Metacognitive Problem-Solving Task for Older Children}

Metacognition, colloquially understood as 'thinking about thinking', is involved in understanding and regulating one's own thinking (Flavell, 1979) and is crucial for problemsolving, memorizing, and learning (Schunk \& Zimmerman, 1994; Wang et al., 1990). It often includes two core components: (1) metacognitive knowledge - understanding one's own cognitive strategies and how they affect learning - and (2) metacognitive skills - regulation of these cognitive strategies. Metacognitive knowledge is important for explaining test performance (e.g., Roebers et al., 2012; 2014), whereas metacognitive skills explain individual differences in test performance even after controlling for other cognitive skills (Van der Stel \& Veenman, 2008). It is important to study metacognition in children because it is related to academic attainment and success at work (Ohtani \& Hasasaka, 2018; Zimmerman \& Bandura, 1994).

Metacognitive skills can be sub-classified as: (i) metacognitive monitoring; (ii) metacognitive control; and (iii) metacognitive evaluation. Metacognitive monitoring is the awareness of one's cognitive processes and evaluating progress on an ongoing task (e.g., Roebers \& Spiess, 2017). Metacognitive control is the regulation of cognition and behavior depending on one's metacognitive knowledge and feedback from other metacognitive skills (e.g., Flavell, 1987; Schraw \& Moshman, 1995). Metacognitive evaluation (or metacognitive accuracy) is the prediction (also called judgement of knowing) or evaluation (or retrospective confidence judgement) of task accuracy (e.g., Bryce \& Whitebread, 2012; Flavell, 1987). Even though they interact with each other, these three are fundamentally different skills. Most tasks only measure single components, making it difficult to establish content validity.

In a major review, Veenman et al. (2006), emphasized the need for comprehensive, ageappropriate, holistic metacognition assessment metrics. There is a substantial amount of cognitive advancement between early childhood and adulthood, including metacognition and executive function (Best \& Miller, 2010; Veenman et al., 2004). However, little attention has 
been paid to metacognition skill development throughout childhood. There are limited metrics available for late childhood, especially those tapping into metacognition of problem-solving (although see Armour-Thomas \& Haynes, 1988). Additionally, there are no tasks that individually measure a range of metacognitive skills. That is, there are no tasks to study the development of metacognition from early to late childhood, resulting in reduced understanding of this area of cognitive development. Additionally, the tasks for very young children and adults are difficult to compare, leading to a further deficit in understanding metacognition development.

Metacognition measurement with older children is challenging for five key reasons. First, metacognition is made up of multiple components, but tasks tend to narrow down and test only a single metacognitive component rather than the whole construct, resulting in poor content validity. Second, measurements might not be a true reflection of the construct itself because of its complexity, making it difficult to reach good criterion validity. Third, measurement tools are confounded by and correlated with other cognitive processes (e.g., the literacy and workingmemory skills needed to processing instructions). Fourth, there is a growing divide between metrics used to assess metacognition in adults (questionnaires, judgement metrics) and children (think aloud, observational). Fifth, tasks meant for younger children or adults lead to ceiling and floor effects when used with the other group.

Common tools for measuring metacognition have many limitations when measuring metacognitive abilities in late childhood. Questionnaires, interviews (verbal self-report) and judgement metrics have been used widely to assess metacognitive knowledge in adults (Schraw \& Dennison, 1994) because of the advantage of large-scale administration. However, they are limited by individual biases in self-report metrics (Veenman, 2005), metacognition's nonconscious nature and over a reliance on verbal ability (Whitebread et al., 2009). Prospective judgement (predictions of one's performance before a task) and retrospective judgement (estimation of one's performance after a task) metrics are used to assess metacognitive evaluation (e.g., Lockl \& Schneider, 2002). They have been used in a variety of contexts, 
including reading comprehension (e.g., Schraw 2009), metamemory (e.g., Nelson \& Nahrens, 1990) and knowledge (Roebers et al., 2009) However, they may be unsuitable for children because individual biases and score variabilities might not link to the task (Veenman et al., 2006). Some studies use pre/post-task evaluation measurements equated to monitoring, conflating the two. Newer metrics code for monitoring with participants completing a task using think-aloud or experimental protocols involving observational coding of children's behaviors on problem-solving tasks (Bryce \& Whitebread, 2012).

Think-aloud strategies are popular in studies with children because they allow researchers to measure unobservable and nonconscious aspects of the thinking process allowing for a better and deeper understanding of the metacognitive processes (Schraw \& Moshman, 1995). However, they could be constrained by verbal proficiency and might produce significant increases in cognitive load for children, conflating and distorting task performance (Whitebread et al., 2009). Observational tasks and checklists that record what children do rather than their perception or memory of it are more suitable (Winne \& Perry, 2000). For example, Bryce and Whitebread (2012) developed an observational problem-solving task that coded metacognitive skills while young children completed a train track task (metacognitive monitoring and metacognitive control). However, observational protocols are time-intensive, limiting the scale and statistical rigor of quantitative studies. Additionally, they usually require video recordings, which leads to several ethical constraints (especially in children and in understudied/vulnerable populations). Vo et al. (2014) developed non-verbal tasks of retrospective judgements for young children involving accuracy on numerosity discrimination (Which has more?; How sure are you?) and an emotional valence discrimination (Who is happier?; How sure are you?). However, they only measured metacognitive evaluation, not other aspects of metacognition.

The goal of the current study is to address the aforementioned gap and build an understanding of metacognition development by using a new metric that can be used with younger children, adolescents and adults - the Zoo task (Ellefson et al., 2020, 
https://osf.io/c6aq7/). We had a special opportunity to study an understudied population of children from ethnic minority, high poverty, urban communities. There were several data collection limitations including time constraints, the need for group administration, ethical issues of video recording children and data processing from a large number of children that we had to consider when accessing this under studied population. We developed a novel cognitive task that captures the key metacognitive skills (monitoring, control, and evaluation), and limits the confounding effects of verbal/literacy skills. The task can be scaled to large studies and is ageappropriate while still using metrics that are similar to adults and is important for better understanding of how metacognition develops throughout childhood.

\section{Method}

\section{Participants}

The study included 204 children (Ages: $M=9.32$ years, $S D=0.81$, range $=7.84-11.99$ years; Gender: $n=95$ females). The data were collected during or after school hours from elementary schools in high poverty urban areas in the eastern United States $(n=174$ African American, 2 Asian, 16 Latino, 5 Caucasian, 4 Mixed, 3 undeclared). The data reported here are from the baseline testing of a larger sample of third to fifth grade students participating in an after-school chess program (see https://osf.io/yac8e) that included a general cognitive ability task (Ravens Standard Progressive Matrices: raw score $M=30.97, S D=9.41$; percentile $M=$ 46.11, $S D=29.18$; age equivalent $M=12.07, S D=5.29)$ and three subsets of the Stanford 10 (Harcourt Assessment, 2003; grade equivalents for reading comprehension $M=3.75, S D=$ 2.28; math problem solving $M=3.88, S D=1.99$; science reasoning $M=3.99, S D=2.62$ ).

\section{Design, Materials \& Procedures}

The study received ethical approvals from multiple institutions: University of Cambridge's Psychology Research Ethics Committee (IRB 2011.39), Virginia State University (IRB 1011-37), 
and Virginia Commonwealth University (IRB HM20000017). Children received a \$10 gift card and small prizes for taking part in the full battery of tasks collected alongside the Zoo Task.

This study includes two cognitive tasks: First, a novel metacognitive problem-solving task that uses multiple metrics of metacognitive skills during a planning task; and second, a standard metacognitive memory task. The main goal is to evaluate the metacognitive metrics in our new metacognition task. Both the tasks included metrics of accuracy, metacognitive evaluation metrics (absolute accuracy index and bias index) - the key variables used in the reliability, validity and regression analyses. Both tasks were designed to be included in a 3-hour battery of baseline testing. The constraints of the larger project meant that all tasks in the overall project had to use group administration so that the baseline battery could be collected in under one week so that the chess club could begin without much delay. To allow for this large-scale group testing, the Zoo Task was designed in paper-based format and the metamemory task used a secure website (Thinking Games; see http://instructlab.educ.cam.ac.uk/TGsummary/ for details and example screens). The tasks were designed for schools in high poverty communities and our choices of the tasks included in our research depended on their expectations and constraints. Given that we were studying an underrepresented group, the tasks were adapted to include more universal themes and visual images. Both of the tasks minimized the influences of reading skills and vocabulary by incorporating engaging images, as well as simplified, audiorecorded instructions. Generally, participants started with practice trials where they received some feedback about their performance, followed by unassisted test-trials. Across both tasks, participants were instructed to complete items as quickly as possible while still being accurate.

\section{The Zoo Task - Metacognitive Problem-Solving}

This paper-based task is an adaptation of the errands task, designed for adults (HayesRoth \& Hayes-Roth, 1979) and modified for children (Radziszewska \& Rogoff, 1988; 1991). The full task (Ellefson et al., 2020, https://osf.io/c6aq7/) and pilot data (Patel et al., 2020, https://osf.io/gkac3/) are openly available. At the start of the task, researchers read the 
instructions aloud to the participants, highlighting how they help the zookeeper feed some animals before getting back on the school bus. Participants were encouraged to find the shortest route to feed the animals, making sure that they start at the start point and end at the end point, while also being sure that they stay on the paths and avoid going across the cages. Next, participants drew lines to indicate the most efficient path to feed animals from two practice lists (each with two animals). The key trials had four (Trial 1), six (Trial 2) and eight animals (Trial 3). The number of animals was used to increase the difficulty across the trials. A variety of animals were visited across the lists and were selected to cover a good amount of the map. All children had the same list of animals to visit. Before and after each trial, participants made prospective and retrospective confidence judgements, respectively. The participants indicated their confidence using a set of five smiley faces (very sad, sad, neutral, happy, very happy).

Scoring included accuracy and metacognitive metrics based on the paths that the children created to feed the animals. An accuracy score accounted for the difference between the participant's absolute path-length and the shortest path possible, while factoring in the number of required animals visited and their relative weightage. Additionally, the paths generated were coded on seven categories: a clear route, all animals seen, using the start and finish, going to the dots, not following the list in order, not backtracking, evidence of a strategy (e.g., checking off animals). Each category score was either 0,1 or 2 points.

The monitoring metric is based on awareness of cognition, while the metacognitive control metric is based on regulation of cognitive strategies. A metacognitive monitoring score captured instances of error detection and following the given instructions. It included starting at "start" and ending at "finish", visiting all animals and sticking to paths between cages (range $=0$ to 6).

Metacogntive Monitoring $=$ visiting start and end points + all animals visited + visiting cage entrances and using paths between cages Eq. 1 
A metacognitive control score included instances of seeking strategies, changes in strategies (corresponding to persistence of error), not backtracking and efficiency of the order animals visited (range $=0$ to 8$)$.

Metacogntive Control $=$ not backtracking + order of animals visited + strategies used + changes in strategies

Participants' confidence of their accuracy before (prospective) and after (retrospective) each trial. These were converted into two metacognitive evaluation scores: absolute accuracy index and bias index (Schraw, 2009).

$$
\begin{aligned}
& \text { Absolute Acuracy Index }=\frac{1}{N} \times \sum_{i=1}^{N}\left(\text { confidence }_{i}-\text { accuracy }_{i}\right)^{2} \quad \text { Eq. } 3 \\
& \text { Bias Index }=\frac{1}{N} \times \sum_{i=1}^{N}\left(\text { confidence }_{i}-\text { accuracy }_{i}\right)
\end{aligned}
$$

The absolute accuracy index is the difference between judgement and accuracy. The bias index is the degree of over and under-confidence of the prospective and retrospective judgements.

\section{Metamemory Task}

Several metamemory tasks have been developed as measures of metacognition of memory with adults and children; this metamemory is a subset of metacognition (e.g., Lockl \& Schneider, 2002). This adaptation of a standard metamemory task (Everson et al., 1994) measures participants' memory of a pair of images and metacognitive evaluation of the memory. We used pairs of pictures that children commonly encounter (i.e., furniture, animals, vegetables and tableware). The task is split into three phases: learn, break and recall. During the learn phase, participants saw 24 pairs of pictures for 5 seconds each. After each pair, they were asked to make a prospective judgement about their memory of that pair based on the same retrospective judgements used during the Zoo Task. Next, during a break phase, participants saw a counter, counting backwards from 100. Finally, during the recall phase, participants saw 24 pairs of pictures and asked if they had seen the exact pair before in the learn phase. After 
this decision, they made a retrospective judgement for each pair. Again, all confidence judgements were made using the five smiley faces.

During the recall phase, there were three sets of picture-pairs. Learning-items were 12 picture-pairs shown during both the learn and recall phases. Mixed-items were 8 picture-pairs where one picture was seen during the learn phase and one picture was new. New-Items were 4 picture-pairs shown only during the recall phase (prospective judgement isn't possible to collect for this picture-pair set). The images used for the picture-pairs were selected from Rossion and Pourtois (2004). Relatedness ratings from Becker et al. (2009) were used to create related/unrelated picture-pairs. Across all phases and item types, $50 \%$ were related and $50 \%$ were unrelated. The picture-pairs in the learn and recall phases were presented in random order. We collected accuracy of each memory decision responses for each judgement.

\section{Data Processing and Analyses}

Scaled accuracy and judgements were used throughout because the bias and absolute accuracy indices were computed using subtraction procedures and the scores needed to be in the same range. More specifically, the range of scores for all were scaled to between 0 and 1. The score for the five smiley faces was $0, .25, .50, .75$, and 1.0 for the sad, slightly sad, neutral, slightly happy and happy faces, respectively. We winsorized the data to correct for outliers. Residuals were normally distributed and uniformly distributed against the predicted values. Separate analyses using standardized data (rather than the scaled scores) revealed similar trends. Therefore, only the raw data analyses are reported here.

Exploratory-factor-analysis was used for preliminary analyses to allow data reduction. The results indicated that three elements could be combined: (1) the three trials in Zoo Task, (2) the prospective and retrospective bias indices (in both the Zoo and metamemory tasks); and (3) the prospective and retrospective absolute accuracy indices in (both the Zoo and metamemory tasks). However, the results also indicated that the three different picture-pair sets in the metamemory task (i.e., learned, mixed, new) could not be combined. 
Reliability was evaluated with internal consistency and inter-rater reliability. Cronbach's alpha was used to explore the properties of items/levels on the Zoo Task. All of the metacognitive monitoring and control metrics were determined by two coders, while the accuracy coding was tested using $10 \%$ of the data selected randomly using data from every 4 th, 14th, 24th... child from a given school. The number four was generated using a random number generator. Intraclass correlations were used to test coder reliability on this subset of data.

Validity was judged with criterion (concurrent) and divergent (discriminate) tests. Criterion validity was assessed by comparing the Zoo and metamemory tasks because they have some shared metacognition properties (see Supplemental Material for hierarchical regressions). However, they do not measure exactly the same aspects of metacognition and should not correlate strongly nor provide a pure test of criterion validity. Divergent validity was evaluated by correlating the Zoo metrics with performance on a variety of executive function tasks (Ellefson et al., 2017), a Growth Mindset questionnaire (Dweck, 2000), a general cognitive ability task (Raven et al., 2008), and the reading comprehension, math problem solving and science Stanford 10 subsets (Harcourt Assessment, 2003) - all collected as part of the larger study.

\section{Results \& Discussion}

There was good internal consistency across the three Zoo trials (Trials1 \& 2: $r(201)=.56$, Trials $1 \& 3, r(201)=.60$, Trials $2 \& 3: r(201)=.48$, all correlations $p<.001$ and medium effect size). The dataset had a good Cronbach's alpha ( $\alpha=.77$; and a drop when any trial is excluded).

Overall, intraclass correlation coefficients were strong. Coefficients were classed as excellent (Cicchetti, 1994) for accuracy $(I C C=.95)$, two metacognitive control metrics (ICC $=.83$ for strategy; ICC $=.82$ for order of animals visited) and two metacognitive monitoring metrics $(\mathrm{ICC}=.86$ for visiting only cage entrances $\&$ keeping to paths; ICC $=.79$ for using start and end points). The coefficients were classed as good for drawing a clear path (ICC = .74), 
one metacognitive monitoring metric (ICC $=.70$ for not backtracking) and one metacognitive control metrics (ICC $=.72$ for all animals visited).

Partial correlation analyses (controlling for age) of the Zoo and metamemory tasks, indicated small to medium effect-size correlations, with the bias and absolute accuracy indices showing negative correlations, where expected (see Table 1).

\section{Table 1}

Partial Correlations (Controlling for Age) Between the Zoo and Metamemory Tasks

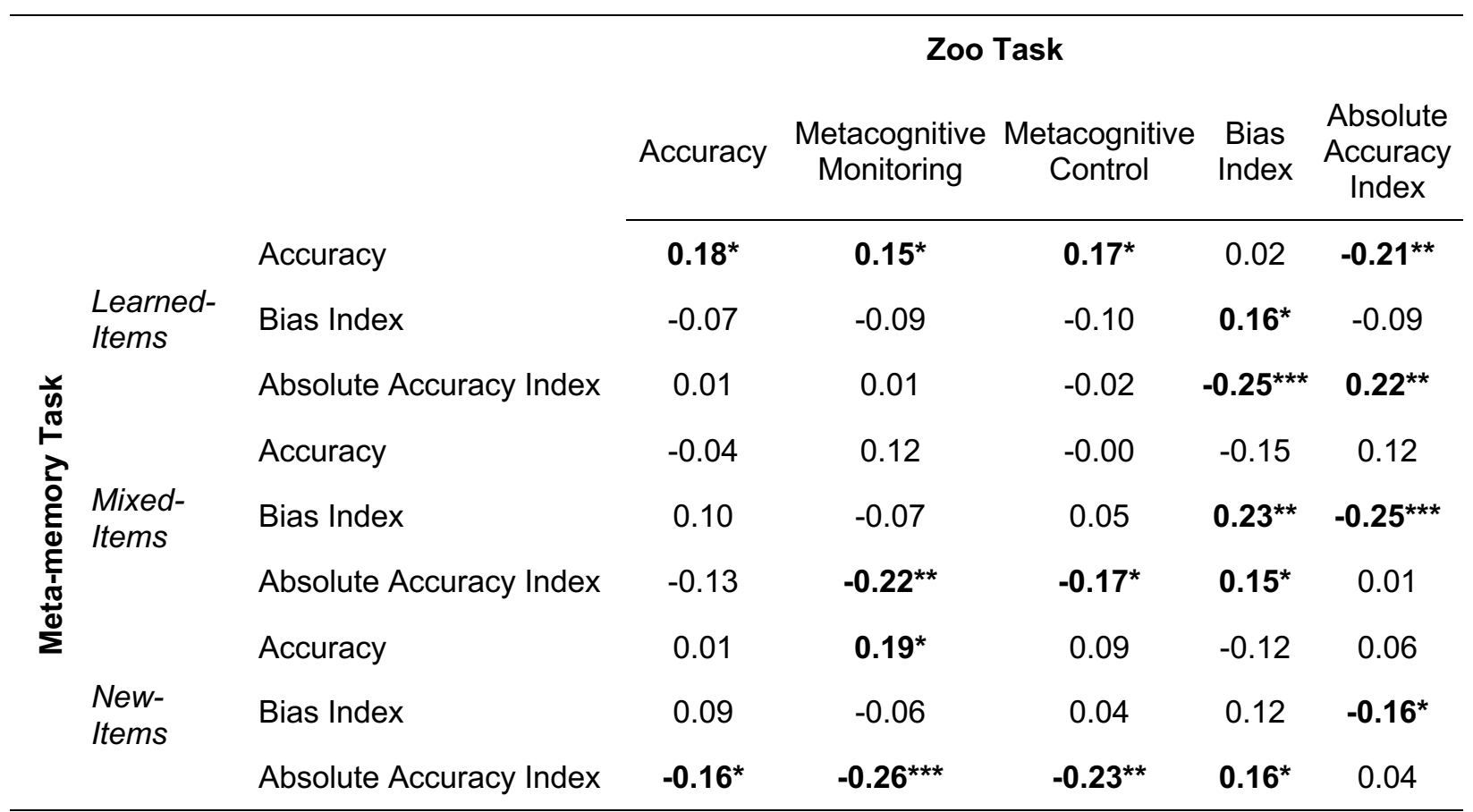

Notes $-{ }^{*} p<.05,{ }^{* *} p<.01,{ }^{* * *} p<.001$. See Supplemental Material for exact $p$-values.

The metacognitive metrics are significantly correlated with the reading comprehension, math problem solving and science scores, executive function skills and general cognitive ability, but not with growth mindset (see Figure 1). The finding corresponds to well-established links between metacognition and other cognitive skills as well as school success (e.g., Ohtani \& Hasasaka, 2018; Zimmerman \& Bandura, 1994). 
The Zoo Task scores appear to be age-appropriate and reliable (internal consistency and inter-rater reliability). The initial findings suggest adequate validity. However, more comparisons to metacognitive and additional cognitive measures (e.g., language proficiency) are needed to fully establish convergent or divergent validity. The results indicate that the Zoo metrics are scalable, measure a range of metacognitive skills, and are similar to metrics used in adult tasks without encountering ceiling or floor effects. The similar overall scores across the tasks suggest that the metrics have a similar difficulty level. These initial findings indicate that the Zoo Task can bridge existing metrics of metacognition in young children and adults. Additionally, it minimizes the researcher's role (which increases scalability), reduces attendant biases, reduces literacy requirements, doesn't require video recording and affords administration across different language groups. 


\section{Figure 1}

Zoo Task Correlations with the Metamemory Task Metrics as well as Executive Functions,

\section{Academic Achievement, Growth Mindset and General Cognitive Ability}

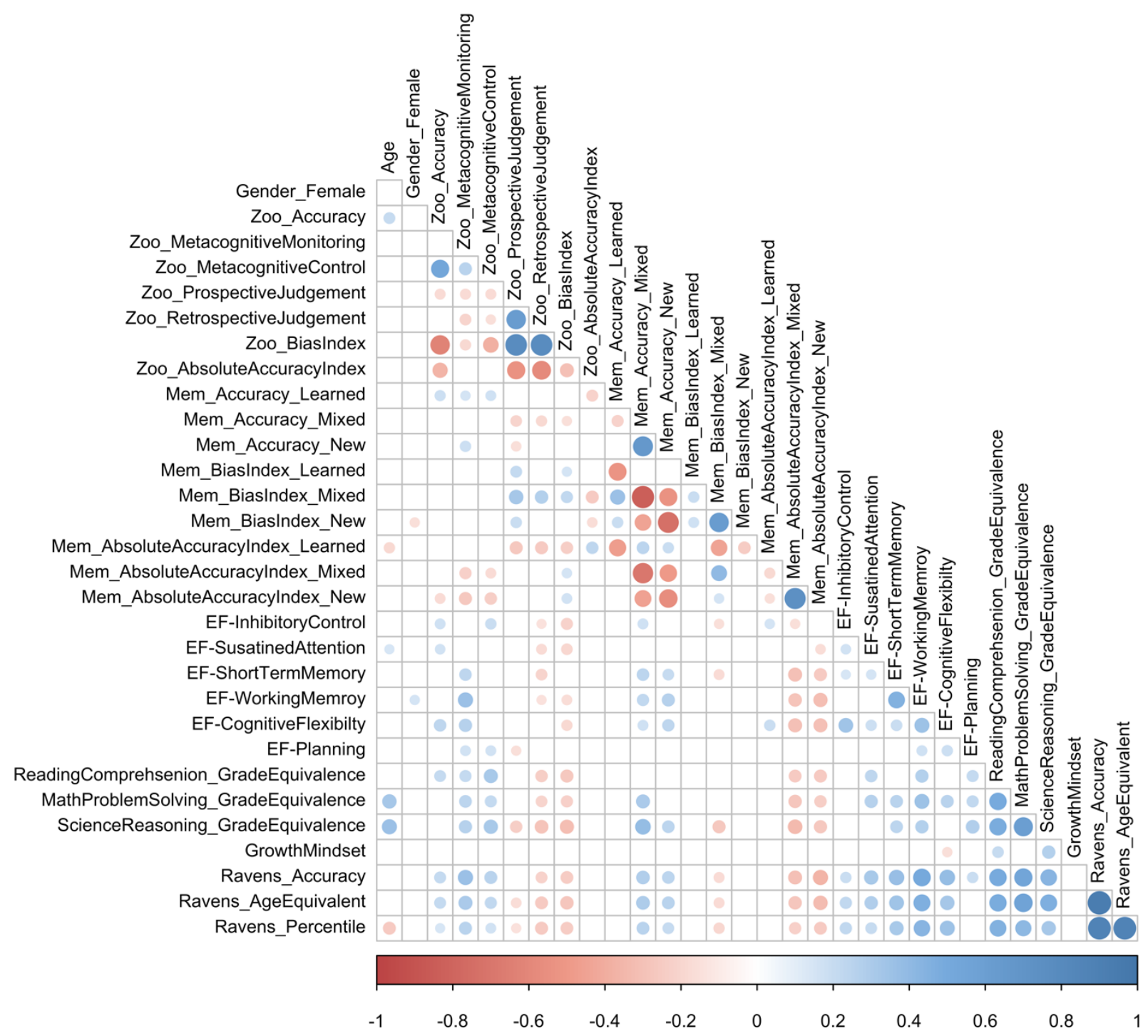

Notes. Dot size and color indicate correlation strength (blank not significant). Exact correlation coefficients in Supplemental Material. 
Metacognition tasks with children have primarily depended on observational tasks or behavior ratings as children have been consistently found to be overconfident with their judgement ratings (Finn \& Metcalfe, 2014). This overconfidence results not from poor metacognitive abilities (Kruger \& Dunning, 1999), as previously assumed, rather from wishful thinking and a lack of differentiation of expectation from their wishes (Schneider, 1998; van Loon et al., 2017). The overconfidence bias on the metamemory task makes it increasingly problematic to be used with children and reduces the potential validity of metacognitive evaluation (as these metrics become measures of task performance rather than of metacognition), potentially leading to a weak association between the two tasks. The Zoo Task, unlike the metamemory task, captures other metacognitive metrics while students perform a given task (i.e., metacognitive control and monitoring) that are not affected by the overconfidence bias. Capturing all three metacognitive skills (metacognitive control, monitoring and evaluation) increases the content validity of the items. However, the current comparisons focus on content validity for metacognitive evaluation. Further research should test content validity for metacognitive monitoring and control.

The results could have been affected by the sampling bias. Ethnic minority, low socioeconomic status participants are considered to have low cognitive levels (Blair et al., 2011), as demonstrated by high overconfidence in judgement metrics and low general cognitive ability age-matched scores. In addition, the data collected here required small-group administration because of the constraints of the overall project. Further development of this task should include comparing it to metrics collected from other tasks involving one-to-one administration.

The Zoo Task is able to capture high variability in participants' accuracy and metacognitive monitoring, suggesting that the task could be age appropriate for an even larger age group than included here. Further use of the task across different age groups would help better understand metacognitive development across years. Additionally, comparison of the task performance with the errands task performance (Hayes-Roth \& Hayes-Roth, 1979) in adults will 
allow for comparison of metacognitive abilities across longer time spans and nuanced understanding of cognitive development. However, creating a reliable way to measure response times (i.e., converting from paper to computerized administration) will be an important step towards making this task appropriate for a wide range of ages.

The Zoo Task only measures metacognitive skills and not metacognitive knowledge. Most tasks seem to be good at measuring one or the other and a full understanding of metacognition involves multiple tasks. Further research should explore how performance on the Zoo Task is linked to reliable measures of metacognitive knowledge.

The Zoo Task makes a methodological and theoretical contribution to the field as this novel problem-solving metacognitive task includes scores that are reliable and valid based on this large sample. It provides metacognition researchers with a much-needed age-appropriate metric that could be used with older children. As opposed to commonly used tasks, including scalable metamemory tasks that only measure metacognitive evaluation, observational problem-solving tasks that limit the sample size and highly subjective self-report questionnaires, this novel task allows researchers to holistically metric multiple metacognitive skill components on a large-scale basis. The Zoo Task captures all three different components of metacognition; control (the ability to regulate one's thought processes), monitoring (awareness of one's thought processes) and evaluation (prediction or judgement before or after task completion). This holistic measurement allows for the use of a single task to measure all components rather than three separate tasks. The task also helps gather preliminary data on metacognitive levels and development in children in late childhood and early adolescence.

\section{References}

Armour-Thomas, E., \& Haynes, N. M. (1988). Assessment of metacognition in problem solving. Journal of Instructional Psychology, 15, 87. 
Becker, M., Kipp, K., \& Mecklinger, A. (2009). Database of semantically associated and unassociated pairs of everyday objects for the study of memory in children: Technical report. https://publikationen.sulb.uni-saarland.de/bitstream/20.500.11880/23354/1/ PictureDatabase SemanticAssociation TechnicalReport.pdf

Best, J. R., \& Miller, P. H. (2010). A Developmental Perspective on Executive Function. Child Development, 81, 1641-1660. https://doi.org/10.1111/j.1467-8624.2010.01499.x

Blair, C., Granger, D. A., Willoughby, M., Mills-Koonce, R., Cox, M., Greenberg, M. T., Kivlighan, K. T., Fortunato, C. K., \& FLP Investigators. (2011). Salivary cortisol mediates effects of poverty and parenting on executive functions in early childhood. Child Development, 82, 1970-1984. https://doi.org/10.1111/j.1467-8624.2011.01643.x

Bryce, D., \& Whitebread, D. (2012). The development of metacognitive skills: evidence from observational analysis of young children's behavior during problem-solving. Metacognition and Learning, 7, 197-217. https://doi.org/10.1007/s11409-012-9091-2

Cicchetti, D. V. (1994). Guidelines, Criteria, and Rules of Thumb for Evaluating Normed and Standardized Assessment Instruments in Psychology. Psychological Assessment, 6, 284290. https://doi.org/10.1037/1040-3590.6.4.284

Dweck, C. S. (2000). Self-theories: Their role in motivation, personality and development, Psychology Press.

Ellefson, M.R., Ng, F.F., Wang, Q., \& Hughes, C. (2017). Efficiency of executive function: A twogeneration cross-cultural comparison of samples from Hong Kong and the United Kingdom. Psychological Science, 28, 555-566. https://doi.org/10.1177/0956797616687812

Ellefson, M. R., Serpell, Z., \& Parr, T. (2020). The Zoo Task. Retrieved from https://osf.io/c6aq7 Everson, H. T., Smodlaka, I., \& Tobias, S. (1994). Exploring the relationship of test anxiety and metacognition on reading test performance: A cognitive analysis. Anxiety, Stress, \& Coping, 7, 85-96. https://doi.org/10.1080/10615809408248395 
Finn, B., \& Metcalfe, J. (2014). Overconfidence in children's multi-trial judgments of learning. Learning and Instruction, 32, 1-9. https://doi.org/10.1016/J.LEARNINSTRUC.2014.01.001 Flavell, J. H. (1979). Metacognition and cognitive monitoring: A new area of cognitivedevelopmental inquiry. American Psychologist, 34, 906-911. https://doi.org/10.1037/0003$\underline{066 X .34 .10 .906}$

Flavell, J. H. (1987). Speculations about the nature and development of metacognition. In F. E. Weinert \& R. H. Kluwe (Eds.), Metacognition, motivation and understanding (pp. 21-29). Lawrence Erlbaum Associates.

Harcourt Assessment Inc. (2003). Stanford achievement test series tenth edition. Pearson Education.

Hayes-Roth, B., \& Hayes-Roth, F. (1979). A cognitive model of planning. Cognitive Science, 3, 275-310. https://doi.org/10.1016/S0364-0213(79)80010-5

Kruger, J., \& Dunning, D. (1999). Unskilled and unaware of it: How difficulties in recognizing one's own incompetence lead to inflated self-assessments. Journal of Personality and Social Psychology, 77, 1121-1134. https://doi.org/10.1037/0022-3514.77.6.1121

Lockl, K., \& Schneider, W. (2002). Developmental trends in children's feeling-of-knowing judgements. International Journal of Behavioral Development, 26, 327-333. https://doi.org/10.1080/01650250143000210

Nelson, T. O., \& Narens, L. (1990). Metamemory: A theoretical framework and new findings. In G. Bower (Ed.), The psychology of learning and motivation (Vol. 26, pp. 125-173). Academic Press.

Ohtani, K., \& Hisasaka, T. (2018). Beyond intelligence: a meta-analytic review of the relationship among metacognition, intelligence, and academic performance. Metacognition Learning, 13, 179-212. https://doi.org/10.1007/s11409-018-9183-8

Patel, J. N., Aldercotte, A., Tsapali, M., Serpell, Z., Parr, T., \& Ellefson, M. R. (2020). The Zoo Task: A Novel Metacognitive Problem-Solving Task Developed with a Sample of African 
American Children from Schools in High Poverty Communities. Retrieved from https://osf.io/gkac3/

Radziszewska, B., \& Rogoff, B. (1988). Influence of adult and peer collaborators on children's planning skills. Developmental Psychology, 24, 840-848. https://doi.org/10.1037/0012$\underline{1649.24 .6 .840}$

Radziszewska, B., \& Rogoff, B. (1991). Children's guided participation in planning imaginary errands with skilled adult or peer partners. Developmental Psychology, 27, 381-389. https://doi.org/10.1037/0012-1649.27.3.381

Raven, J. C., Styles, I., \& Raven, M. A. (1998). Raven's progressive matrices: SPM plus test booklet. Oxford Psychologists Press.

Roebers, C. M., Cimeli, P., Röthlisberger, M., \& Neuenschwander, R. (2012). Executive functioning, metacognition, and self-perceived competence in elementary school children: an explorative study on their interrelations and their role for school achievement. Metacognition and Learning, 7, 151-173. https://doi.org/10.1007/s11409-012-9089-9

Roebers, C. M., Krebs, S. S., \& Roderer, T. (2014). Metacognitive monitoring and control in elementary school children : The interrelations and their role for test performance. Learning and Individual Differences, 29, 141-149. https://doi.org/10.1016/j.lindif.2012.12.003

Roebers, C. M., Schmidt, C., and Roderer, T. (2009). Metacognitive monitoring and control processes in primary school children's test performance. British Journal of Educational Psychology, 79, 749-767. https://doi.org/10.1348/978185409X429842

Roebers, C. M., \& Spiess, M. (2017). The development of metacognitive monitoring and control in second graders: A short-term longitudinal study. Journal of Cognition and Development, 18, 110-128. https://doi.org/10.1080/15248372.2016.1157079

Rossion, B., \& Pourtois, G. (2004). Revisiting Snodgrass and Vanderwart's object pictorial set: The role of surface detail in basic-level object recognition. Perception, 33, 217-236. https://doi.org/10.1068/p5117 
Schneider, W. (1998). Performance prediction in young children: Effects of skill, metacognition and wishful thinking. Developmental Science, 1, 291-297. https://doi.org/10.1111/14677687.00044

Schraw, G. (2009). A conceptual analysis of five measures of metacognitive monitoring. Metacognition and Learning, 4 33-45. https://doi.org/10.1007/s11409-008-9031-3

Schraw, G., \& Dennison, R. S. (1994). Assessing metacognitive awareness. Contemporary Educational Psychology, 19, 460-475. https://doi.org/10.1006/ceps.1994.1033

Schraw, G., \& Moshman, D. (1995). Metacognitive theories. Educational Psychology Review, 7, 351-371. https://doi.org/10.1007/BF02212307

Schunk, D. H., \& Zimmerman, B. J. (1994). Self-regulation of learning and performance: Issues and educational applications. Lawrence Erlbaum Associates.

Snodgrass, J. G., \& Vanderwart, M. (1980). A standardized set of 260 pictures: Norms for name agreement, image agreement, familiarity, and visual complexity. Journal of Experimental Psychology: Human Learning and Memory, 6, 174-215. https://doi.org/10.1037/0278-

\section{$\underline{7393.6 .2 .174}$}

Van der Stel, M., \& Veenman, M. V. J. (2008). Relation between intellectual ability and metacognitive skillfulness as predictors of learning performance of young students performing tasks in different domains. Learning and Individual Differences, 18, 128-134. https://doi.org/10.1016/j.lindif.2007.08.003

van Loon, M., de Bruin, A., Leppink, J., \& Roebers, C. (2017). Why are children overconfident? Developmental differences in the implementation of accessibility cues when judging concept learning. Journal of Experimental Child Psychology, 158, 77-94. https://doi.org/10.1016/j.jecp.2017.01.008

Veenman, M. V. J. (2005). The assessment of metacognitive skills: What can be learned from multi-method designs. In C. Artlet \& B. Moschner (Eds.), Lernstrategien und metakognition: Implikationen für forschung und praxis. Waxmann. 
Veenman, M. V. J., Hout-Wolters, B., \& Afflerbach, P. (2006). Metacognition and learning: conceptual and methodological considerations. Metacognition and Learning, 1, 3-14. https://doi.org/10.1007/s11409-006-6893-0

Veenman, M. V. J., Wilhelm, P., \& Beishuizen, J. J. (2004). The relation between intellectual and metacognitive skills from a developmental perspective. Learning and Instruction, 14, 89-109. https://doi.org/10.1016/j.learninstruc.2003.10.004

Vo, V. A., Li, R., Kornell, N., Pouget, A., \& Cantlon, J. F. (2014). Young children bet on their numerical skills: Metacognition in the numerical domain. Psychological Science, 9, 17121721. https://doi.org/10.1177/0956797614538458

Wang, M. C., Haertel, G. D., \& Walberg, H. J. (1990). What influences learning? A content analysis of review literature. The Journal of Educational Research, 84, 30-43. https://doi.org/10.1080/00220671.1990.10885988

Whitebread, D., Coltman, P., Pasternak, D. P., Sangster, C., Grau, V., Bingham, S., Almeqdad, Q., \& Demetriou, D. (2009). The development of two observational tools for assessing metacognition and self-regulated learning in young children. Metacognition and Learning, 4, 63-85. https://doi.org/10.1007/s11409-008-9033-1

Winne P. H., \& Perry N. E. (2000). Measuring self-regulated learning, in M. Boekaerts, P. R. Pintrich, \& M. Zeidner (Eds.). Handbook of self-regulation (pp. 531-566). Academic Press. Zimmerman, B. J., \& Bandura, A. (1994). Impact of self-regulatory influences on writing course attainment. American Educational Research Journal, 31, 845-862.

https://doi.org/10.3102/00028312031004845 


\section{Supplemental Material}

Method

\section{Table S1}

Demographic Details of Participants from the Pilot and Main Studies

\begin{tabular}{|c|c|c|c|}
\hline & & Pilot Study & Main Study \\
\hline Total Participants & & 45 & 204 \\
\hline \multicolumn{4}{|l|}{ Age in years ${ }^{1}$} \\
\hline & Mean & $10.02(0.99)$ & $9.32(0.81)$ \\
\hline & Range & $7.98-12.56$ & $7.84-11.99$ \\
\hline \multicolumn{4}{|l|}{ Gender } \\
\hline & females & 20 & 95 \\
\hline & males & 25 & 109 \\
\hline \multicolumn{4}{|l|}{ Ethnicity } \\
\hline & African American & 41 & 174 \\
\hline & Asian & 2 & 2 \\
\hline & Latino & 1 & 16 \\
\hline & Caucasian & 0 & 5 \\
\hline & Mixed & 0 & 4 \\
\hline & Undeclared & 1 & 3 \\
\hline
\end{tabular}

Additional variables and data stopping procedures. The current study focuses only on evaluation of the novel metacognitive problem-solving task. The participants are part of a much larger longitudinal study involving data collected at five time-points over two academic years with two different cohorts of children. Each time-point involved a large battery of tasks that included executive functions, general cognitive ability, academic ability, child behaviour, chess skill and attitudes to learning that will be reported independently because of coherence and space limitations. There are further longitudinal data from this novel metacognitive problemsolving task that will be submitted separately, so that we can focus here on the task and measurement only. The two tasks analyzed here are linked specifically to metacognition. As 
outlined in our grant application, we were aiming for an initial sample in the full project of over 200 children to allow enough statistical power to run structural equation models or growth curve modelling on either the full or subsets of data and accounting for possible attrition across the timepoints.

\section{Data Processing and Analyses}

The dataset for this study is openly available from https://osf.io/gkac3.

Missing data. All m participants who completed the Zoo task were used for the analyses. Participants were excluded if they did not complete all three trials or if they didn't enter any of the six judgement scores $(n=9)$. Some did not complete some of their prospective or retrospective judgments ( $n=47$ participants generating 70 missing judgements out of 1224 total judgements or $5.7 \%$ ). Missing judgements from these participants were estimated based on the mean of the individual prospective or retrospective judgements, respectively. We looked for whether there were patterns in missing data by gender (female, $n=26$ or $27 \%$; and male, $n=$ 22 or $21 \%$ ), grade (grade $3, n=24$ or $25 \%$, grade $4, n=19$ or $24 \%$ and grade $5, n=5$ or $19 \%$ ) and difficulty level (Trial $1, n=8$ or $.02 \%$; Trial 2, $n=22$ or $.05 \%$; and Trial $3, n=34$ or $.08 \%$ ). These differences were not statistically meaningful, so we assume that they were missing at random.

Some of the participants who completed the zoo task did not complete the metamemory task $(n=28)$; their data was excluded from the cross-task analyses. A small number of trials were randomly missing from the metamemory task $(n=20$ of 9,360 trials or $<.3 \%$ from 3 participants).

Data processing. Exploratory-factor-analysis was used to test if the following could be combined: (1) the three trials in Zoo task, (2) the three different picture-pair sets in the metamemory task; (3) the prospective and retrospective bias indices in the zoo and metamemory tasks; and (4) the prospective and retrospective absolute accuracy indices in the 
zoo and metamemory tasks. Scaled accuracy and judgements were used throughout because the the bias and absolute accuracy indices were computed using subtraction procedures so these scores needed to be on the same range. More specifically, the range of scores for all were scaled to between 0 and 1 . The score for the five smiley faces was $0, .25, .50, .75$, and 1.0 for the sad, slightly sad, neutral, slightly happy and happy faces, respectively. These ranges were selected because of the five different smiley faces used for the judgement and the simple correct or incorrect accuracy for the metamemory task. The data were winsorized to correct for outliers. Residuals were normally distributed and were uniformly distributed against the predicted values, requiring no further transformations on the raw data. Separate analyses using standardized data (rather than the scaled scores) revealed similar trends and therefore results using only the raw data are reported here. 


\section{Results}

\section{Table S2}

Means (standard deviations) of the Zoo Task Measures from the Pilot and Main Studies

\begin{tabular}{lcc}
\hline & Pilot Study & Main Study \\
\hline Accuracy & $.83(.12)$ \\
Metacognitive Control & $2.29(0.99)$ & $1.23(1.16)$ \\
Metacognitive Monitoring & $5.24(0.82)$ & $5.33(0.88)$ \\
Prospective Judgement & & \\
Response & $.75(0.22)$ & $.83(.20)$ \\
Bias index & $.00(.25)$ \\
Absolute accuracy index & & $.09(.12)$ \\
Retrospective Judgement & & $.00(.27)$ \\
Response & & $.10(.14)$ \\
Bias index & & \\
Absolute accuracy index & & $.26)$ \\
\hline
\end{tabular}

Notes: The participants in the pilot study were different from those in the main study. The possible range of scores are as follows: accuracy $=0$ to 1 , metacognitive control $=0$ to 8 , metacognitive monitoring $=0$ to 6 , retrospective/prospective response $=0$ to 1 , retrospective/prospective bias index $=-1$ to 1 , retrospective/prospective absolute accuracy index $=0$ to 1 . 


\section{Preliminary Analyses}

An exploratory factor analysis indicated that the three trials in Zoo task (accuracy) could be reduced to one factor and that it was appropriate to sum the scores across the trials (KMO $=.693$, Bartlett's test of sphericity $\left.X^{2}(3)=178.78 ; p<.001\right)$. The bias indices $(K M O=.500$, Bartlett's test of sphericity $\left.X^{2}(1)=158.08, p<.001\right)$ and the absolute accuracy indices $(K M O$ $=.500$ Bartlett's test of sphericity $\left.X^{2}(1)=77.34, p<.001\right)$ for the prospective and retrospective judgements. The metamemory picture-pair sets could not be combined (Accuracy; KMO $=.482$ ). The prospective and retrospective judgements for a given picture-pair set could be combined for bias indices (Learned-Items; $K M O=.500$, Bartlett's test of sphericity $X^{2}(1)=$ 35.16; $p<.001$ and Mixed-Items; Bartlett's test of sphericity $X^{2}(1)=53.67 ; p<.001$ ) and absolute accuracy indices (Learned-Items; KMO $=.500$, Bartlett's test of sphericity $X^{2}(1)=$ 21.85; $p=.003$ and Mixed-Items; Bartlett's test of sphericity $\left.x^{2}(1)=36.86 ; p<.001\right)$. See Table 2 for the descriptive statistics of the Zoo task from the pilot and main study. The various measures capture a large variability among participants. 


\section{Table S3}

Inter-rater Reliability of the Zoo Task Measures

\section{Intraclass Correlation Coefficients}

\begin{tabular}{lc}
\hline Clear Path Drawn $^{1}$ & .74 \\
Accuracy $^{2}$ & .95 \\
Metacognitive Control $^{1}$ & \\
Not backtracking & .70 \\
Order of animals visited $^{\text {Strategy used }}$ & .82 \\
Metacognitive Monitoring & \\
Visiting start and end points & .83 \\
All animals visited & .79 \\
Visiting cage entrances and using paths between cages & .72 \\
\hline
\end{tabular}

Notes $-{ }^{1}$ Compared raters 1 and 2; Intraclass correlation coefficient estimates were calculated based on two-way mixed effects and a single rater (correlation coefficient calculated on the basis of 186 participants); ${ }^{2}$ Compared raters 2 and 3; Intraclass correlation coefficient estimates were calculated based on two-way mixed effects and single rater (correlation coefficient calculated on the basis of 20 participants). 
THE ZOO TASK

\section{Table S4}

Means (standard deviations) of the Metamemory Measures for the Learned, Mixed and New Picture-Pair Sets

\begin{tabular}{|c|c|c|c|c|}
\hline & Overall & $\begin{array}{l}\text { Learned } \\
\text { Items }\end{array}$ & Mixed Items & New Items \\
\hline Accuracy & $.77(.13)$ & $.84(.16)$ & $.66(.27)$ & $.79(.31)$ \\
\hline \multicolumn{5}{|l|}{ Prospective Judgement } \\
\hline Response & $.63(.18)$ & $.60(.24)$ & $.68(.25)$ & n.a. \\
\hline Bias index & $-.08(.22)$ & $-.15(.26)$ & $.02(.40)$ & n.a. \\
\hline $\begin{array}{l}\text { Absolute } \\
\text { accuracy index }\end{array}$ & $.30(.14)$ & $.25(.17)$ & $.37(.23)$ & n.a. \\
\hline \multicolumn{5}{|l|}{$\begin{array}{l}\text { Retrospective } \\
\text { Judgement }\end{array}$} \\
\hline Response & $.75(.15)$ & $.67(.26)$ & $.86(.17)$ & $.77(.25)$ \\
\hline Bias index & $.04(.17)$ & $.02(.17)$ & $.11(.40)$ & $-.04(.43)$ \\
\hline $\begin{array}{l}\text { Absolute } \\
\text { accuracy index }\end{array}$ & $.25(.13)$ & $.13(.12)$ & $.40(.31)$ & $.31(.36)$ \\
\hline \multirow{2}{*}{\multicolumn{5}{|c|}{$\begin{array}{l}\text { Notes: The possible range of scores are as follows: accuracy }=0 \text { to } 1 \text {, retrospective/prospec } \\
\text { response }=0 \text { to } 1 \text {, retrospective/prospective bias index }=-1 \text { to } 1 \text {, retrospective/prospective }\end{array}$}} \\
\hline & & & & \\
\hline \multicolumn{5}{|c|}{ absolute accuracy index $=0$ to 1 . The overall score isn't used for detailed analyses as it } \\
\hline \multicolumn{5}{|c|}{ combines the different items, however, the data is displayed in the table to give an overview o } \\
\hline
\end{tabular}




\section{Table S5}

Partial Correlations (Controlling for Age) Between the Zoo and Metamemory Tasks with pvalues

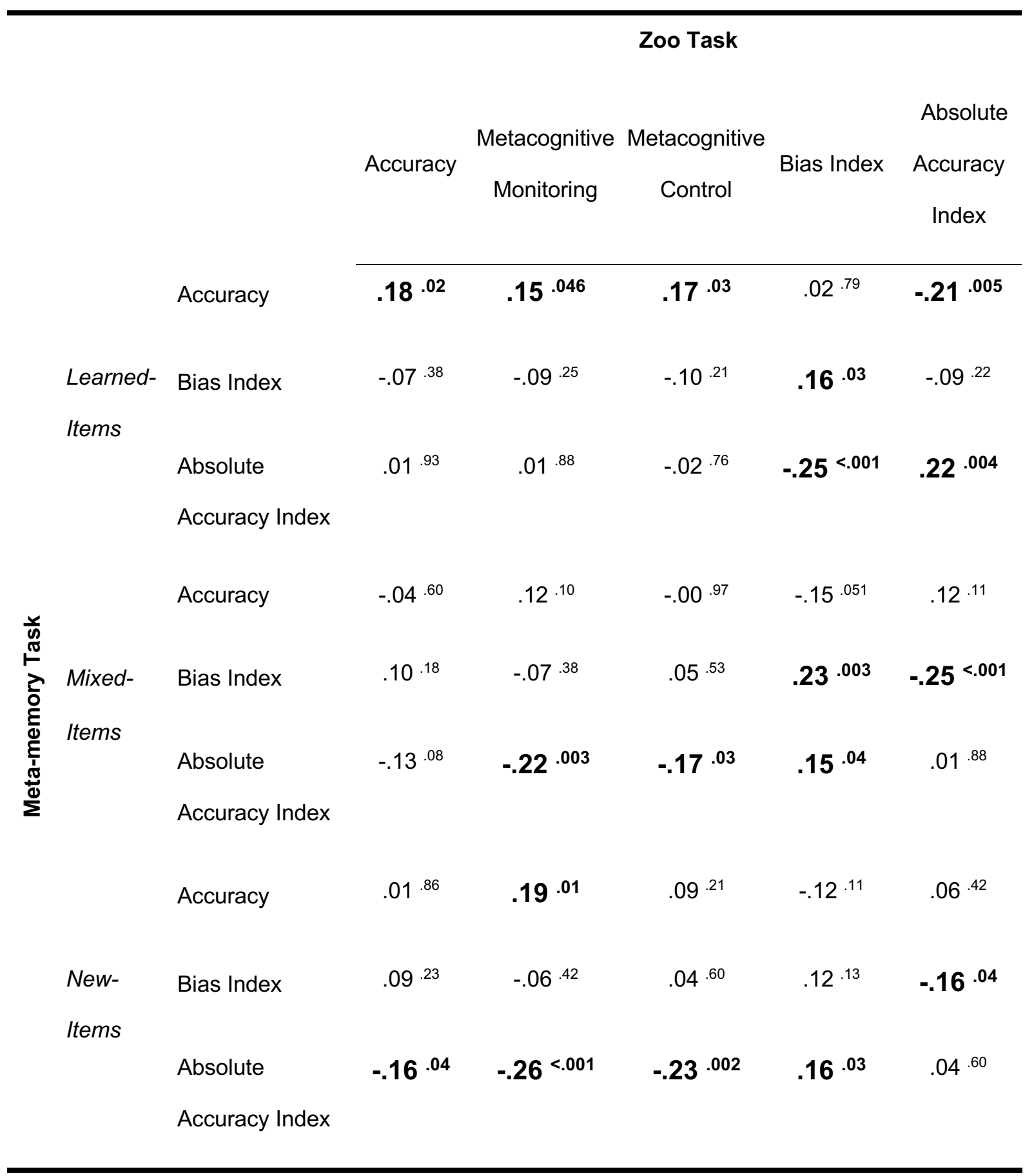

Notes - $p$-values in superscript. 


\section{Figure S1}

Zoo Task Correlations with Other Metacognition, Cognitive, and Academic Measures (raw data)

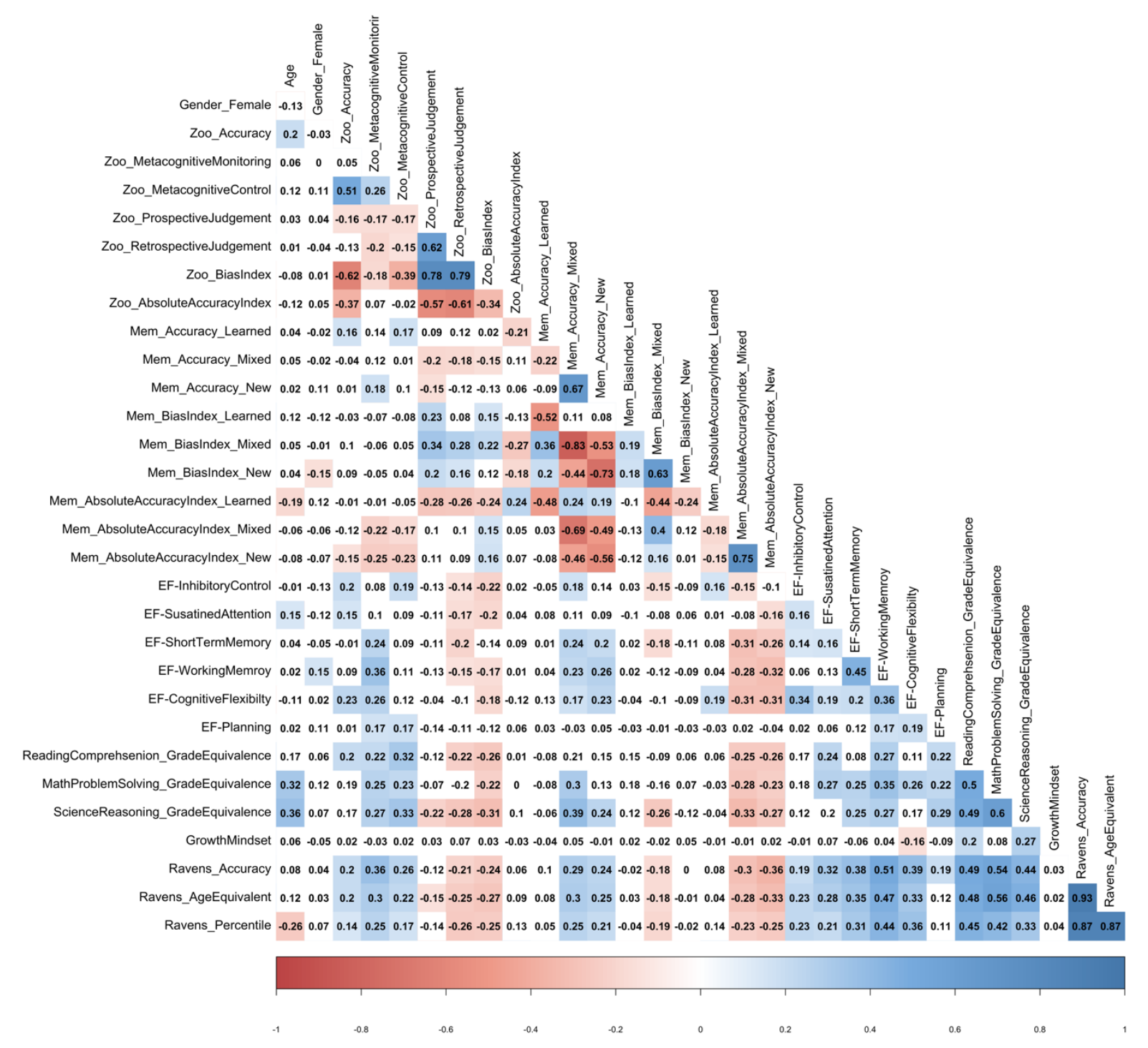




\section{Figure S2}

Zoo Task Correlations with Other Metacognition, Cognitive, and Academic Measures (winsorized data)

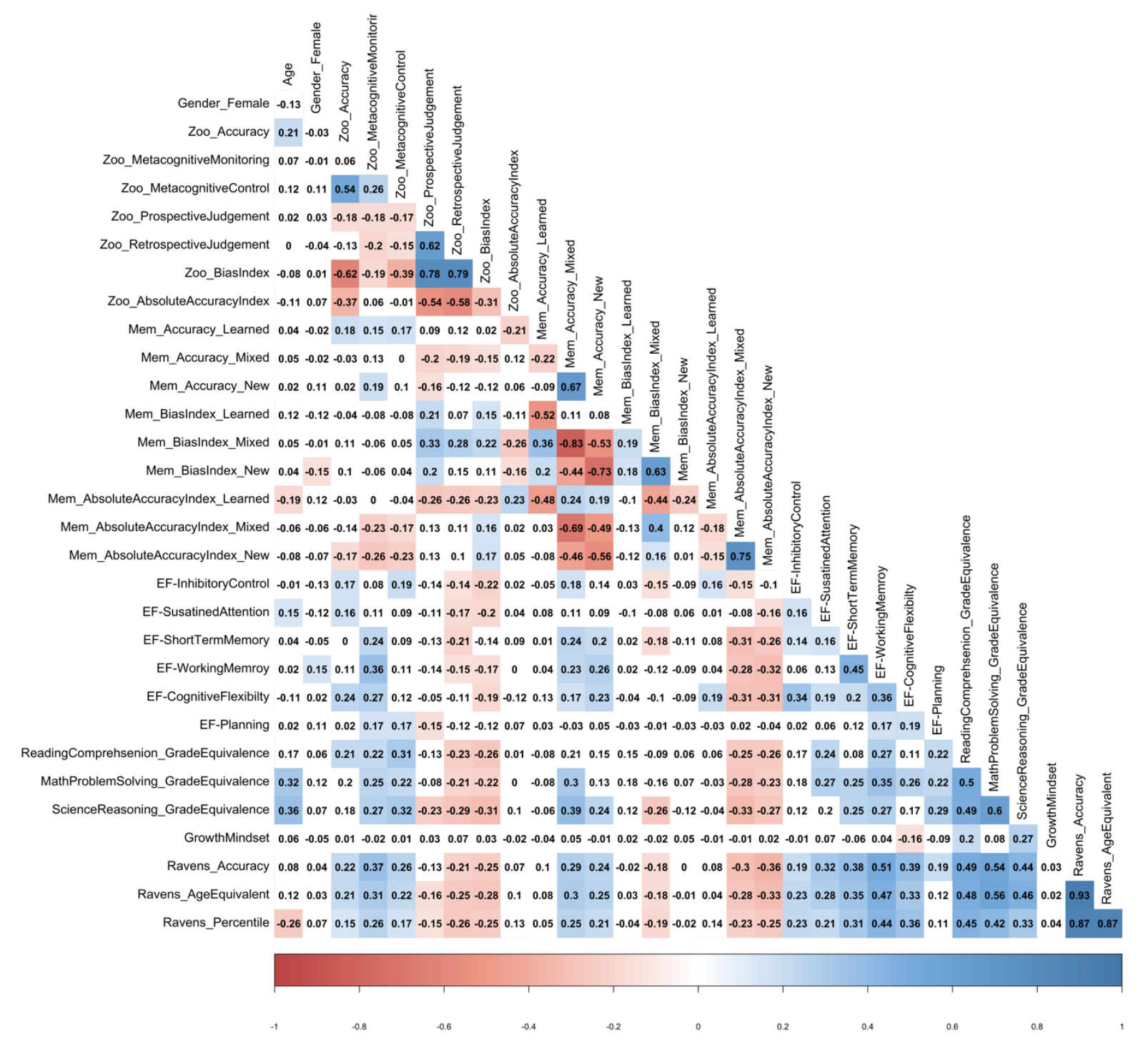




\section{Table S6}

Summary of Significant Zoo Task Predictors of Metamemory Variables for Each of the Three Picture-Pair Sets

\begin{tabular}{|c|c|c|c|c|c|}
\hline \multirow[t]{2}{*}{ Model Summary } & \multicolumn{5}{|c|}{ Parameter Estimates } \\
\hline & B & $\boldsymbol{\beta}$ & $t$ & $p$ & $\delta$ \\
\hline \multicolumn{6}{|l|}{ Learned Items } \\
\hline \multicolumn{6}{|l|}{ Metamemory Accuracy } \\
\hline Zoo metacognitive monitoring & 0.03 & 0.16 & 2.03 & .04 & .02 \\
\hline \multicolumn{6}{|c|}{$F(7,167)=2.59, p=.10, R^{2}=.01$} \\
\hline \multicolumn{6}{|l|}{ Metamemory Absolute Accuracy Index } \\
\hline Age & -0.02 & -0.15 & -2.06 & .04 & .02 \\
\hline Zoo bias index & -0.20 & -0.40 & -2.82 & .01 & .02 \\
\hline \multicolumn{6}{|c|}{$F(7,167)=4.03, p=<.001, R^{2}=.14$} \\
\hline
\end{tabular}

\section{Mixed Items}

Metamemory Accuracy

Zoo bias index

$\begin{array}{llll}-0.41 & -0.36 & -2.38 & .02\end{array}$

$$
F(7,167)=1.63, p=.13, R^{2}=.06
$$

Metamemory Bias Index

\begin{tabular}{lrrrrr} 
Zoo Accuracy & 1.62 & 0.50 & 3.05 & .003 & .08 \\
Zoo bias index & 0.83 & 0.56 & 3.92 & $<.001$ & .10 \\
\cline { 1 - 2 } & $\mathrm{F}(7,167)=4.20, \mathrm{p}=<.001, \mathrm{R}^{2}=.15$
\end{tabular}

Metamemory Absolute Accuracy Index

Zoo metacognitive monitoring $\begin{array}{llll}-0.05 & -0.19 & -2.46 & .01\end{array}$

.04

$$
F(7,167)=2.23, p=.03, R^{2}=.09
$$

\section{New Items}

Metamemory Bias Index ${ }^{1}$

Gender (female) $\begin{array}{lllll}-0.06 & -0.15 & -1.96 & .05 & .06\end{array}$

Zoo metacognitive monitoring

$0.60 \quad 0.34$

2.30

.02

.07

$$
F(7,167)=2.12, p=.04, R^{2}=.08
$$

Metamemory Absolute Accuracy Index ${ }^{1}$

Zoo metacognitive monitoring

$$
F(7,167)=3.31, p=.003, R^{2}=.12
$$


Notes: ${ }^{1}$ Bias index and absolute accuracy index for the new items includes only retrospective judgements (and not prospective judgements) because the New-ltems were administered during the recall phase only. Effect size evaluated using $\delta$ and $R^{2} ; \delta>.01$ - very small effect sizes, $\delta>.20$ and $R^{2}>.02$ - small effect sizes, $\delta>.50$ and $R^{2}>.13$ - medium effect sizes and $\delta$ $>.80$ and $R^{2}>.26$ - large effect size. This table summarizes only significant predictors, see the Supplemental Information for the full regression results. 


\section{Table S7}

All Hierarchical Regression Results for Metamemory Accuracy of the Learned-Items Picture-pair

Set

\begin{tabular}{|c|c|c|c|c|c|}
\hline \multirow[t]{2}{*}{ Model Summary } & \multicolumn{5}{|c|}{ Parameter Estimates } \\
\hline & B & $\beta$ & $t$ & $p$ & $\delta$ \\
\hline \multicolumn{6}{|l|}{ Block 1} \\
\hline Intercept & 0.78 & 0.00 & 5.58 & $<.001$ & \\
\hline Age & 0.01 & 0.04 & 0.46 & .65 & .01 \\
\hline Gender (female) & 0.00 & -0.01 & -0.12 & .90 & .00 \\
\hline \multicolumn{6}{|c|}{$F(2,173)=0.12, p=.88, R^{2}=.00$} \\
\hline \multicolumn{6}{|l|}{ Block 2} \\
\hline Intercept & 0.49 & 0.00 & 1.92 & .06 & \\
\hline Age & 0.00 & -0.02 & -0.32 & .75 & .00 \\
\hline Gender (female) & 0.00 & -0.01 & -0.12 & .90 & .00 \\
\hline Zoo accuracy & 0.29 & 0.21 & 1.24 & .22 & .01 \\
\hline Zoo metacognitive control & 0.01 & 0.08 & 0.89 & .37 & .01 \\
\hline Zoo metacognitive monitoring & 0.03 & 0.16 & 2.03 & .04 & .02 \\
\hline Zoo bias index & 0.11 & 0.17 & 1.19 & .24 & .01 \\
\hline Zoo absolute accuracy index & -0.13 & -0.09 & -0.72 & .47 & .01 \\
\hline \multicolumn{6}{|c|}{$F(7,167)=2.59, p=.10, R^{2}=.01$} \\
\hline
\end{tabular}




\section{Table S8}

All Hierarchical Regression Results for Metamemory Bias Index of the Learned-Items Picture-

Pair Set

\section{Model Summary}

\begin{tabular}{lccccc} 
& B & $\boldsymbol{\beta}$ & $\boldsymbol{t}$ & $\boldsymbol{p}$ & $\boldsymbol{\delta}$ \\
\hline $\begin{array}{l}\text { Block } 1 \\
\text { Intercept }\end{array}$ & -0.27 & 0.00 & -1.73 & .09 & \\
Age & 0.02 & 0.10 & 1.30 & .20 & .02 \\
Gender (female) & -0.02 & -0.11 & -1.40 & .16 & .02 \\
& $F(2,173)=2.18, p=.12, R^{2}=.02$ & & &
\end{tabular}

\section{Parameter Estimates}

\section{Block 2}

Intercept

$\begin{array}{lll}-0.29 & 0.00 \quad-0.99\end{array}$

.33

Age

0.02

0.11

1.38

.17

.02

Gender (female)

$$
-0.02
$$

$-0.10$

$-1.33$

.19

.02

Zoo accuracy

$0.09 \quad 0.05$

0.32

.75

.00

Zoo metacognitive control

$-0.01 \quad-0.05$

$-0.53$

.60

.01

Zoo metacognitive monitoring

$\begin{array}{lllll}-0.01 & -0.05 & -0.66 & .51 & .01\end{array}$

Zoo bias index

0.12

0.17

1.10

.27

.01

Zoo absolute accuracy index

$\begin{array}{lllll}-0.02 & -0.01 & -0.11 & .91 & .00\end{array}$

$$
F(7,167)=1.46, p=.19, R^{2}=.06
$$




\section{Table S9}

All Hierarchical Regression Results for Metamemory Absolute Accuracy Index of the LearnedItems Picture-Pair Set

\begin{tabular}{|c|c|c|c|c|c|}
\hline \multirow[t]{2}{*}{ Model Summary } & \multicolumn{5}{|c|}{ Parameter Estimates } \\
\hline & B & $\beta$ & $t$ & $p$ & $\delta$ \\
\hline \multicolumn{6}{|l|}{ Block 1} \\
\hline Intercept & 0.43 & 0.00 & 4.14 & $<.001$ & \\
\hline Age & -0.03 & -0.18 & -2.32 & .02 & .02 \\
\hline Gender (female) & 0.01 & 0.09 & 1.14 & .25 & .01 \\
\hline \multicolumn{6}{|c|}{$F(2,173)=3.90, p=.02, R^{2}=.04$} \\
\hline \multicolumn{6}{|l|}{ Block 2} \\
\hline Intercept & 0.62 & 0.00 & 3.30 & .00 & \\
\hline Age & -0.02 & -0.15 & -2.06 & .04 & .02 \\
\hline Gender (female) & 0.01 & 0.10 & 1.30 & .19 & .01 \\
\hline Zoo accuracy & -0.22 & -0.21 & -1.28 & .20 & .01 \\
\hline Zoo metacognitive control & -0.01 & -0.05 & -0.57 & .57 & .00 \\
\hline Zoo metacognitive monitoring & -0.01 & -0.04 & -0.50 & .62 & .00 \\
\hline Zoo bias index & -0.20 & -0.40 & -2.82 & .01 & .02 \\
\hline Zoo absolute accuracy index & 0.01 & 0.01 & 0.06 & .95 & .00 \\
\hline \multicolumn{6}{|c|}{$F(7,167)=4.03, p=<.001, R^{2}=.14$} \\
\hline
\end{tabular}




\section{Table S10}

All Hierarchical Regression Results for Metamemory Accuracy of the Mixed-Items Picture-Pair

Set

\begin{tabular}{|c|c|c|c|c|c|}
\hline \multirow[t]{2}{*}{ Model Summary } & \multicolumn{5}{|c|}{ Parameter Estimates } \\
\hline & B & $\beta$ & $t$ & $p$ & $\delta$ \\
\hline \multicolumn{6}{|l|}{ Block 1} \\
\hline Intercept & 0.51 & 0.00 & 2.06 & .04 & \\
\hline Age & 0.02 & 0.05 & 0.59 & .56 & .01 \\
\hline Gender (female) & 0.00 & -0.01 & -0.14 & .89 & .00 \\
\hline \multicolumn{6}{|c|}{$F(2,173)=0.20, p=.82, R^{2}=.00$} \\
\hline \multicolumn{6}{|l|}{ Block 2} \\
\hline Intercept & 1.00 & 0.00 & 2.19 & .03 & \\
\hline Age & 0.02 & 0.06 & 0.79 & .43 & .02 \\
\hline Gender (female) & 0.00 & -0.01 & -0.13 & .89 & .00 \\
\hline Zoo accuracy & -0.79 & -0.32 & -1.86 & .07 & .04 \\
\hline Zoo metacognitive control & 0.00 & 0.02 & 0.19 & .85 & .00 \\
\hline Zoo metacognitive monitoring & 0.03 & 0.08 & 1.03 & .31 & .02 \\
\hline Zoo bias index & -0.41 & -0.36 & -2.38 & .02 & .05 \\
\hline Zoo absolute accuracy index & -0.29 & -0.11 & -0.88 & .38 & .02 \\
\hline \multicolumn{6}{|c|}{$F(7,167)=1.63, p=.13, R^{2}=.06$} \\
\hline
\end{tabular}




\section{Table S11}

All Hierarchical Regression Results for Metamemory Bias Index ${ }^{1}$ of the Mixed-Items Picture-Pair Set

\begin{tabular}{|c|c|c|c|c|c|}
\hline \multirow[t]{2}{*}{ Model Summary } & \multicolumn{5}{|c|}{ Parameter Estimates } \\
\hline & B & $\beta$ & $t$ & $p$ & $\delta$ \\
\hline \multicolumn{6}{|l|}{ Block 1} \\
\hline Intercept & -0.13 & 0.00 & -0.42 & .68 & \\
\hline Age & 0.02 & 0.05 & 0.66 & .51 & .02 \\
\hline Gender (female) & 0.00 & 0.00 & -0.01 & .99 & .00 \\
\hline \multicolumn{6}{|c|}{$F(2,173)=.23, p=.80, R^{2}=.00$} \\
\hline \multicolumn{6}{|l|}{ Block 2} \\
\hline Intercept & -1.33 & 0.00 & -2.34 & .02 & \\
\hline Age & 0.00 & 0.01 & 0.09 & .93 & .00 \\
\hline Gender (female) & 0.00 & 0.00 & -0.01 & .99 & .00 \\
\hline Zoo accuracy & 1.62 & 0.50 & 3.05 & .003 & .08 \\
\hline Zoo metacognitive control & 0.00 & -0.01 & -0.16 & .87 & .00 \\
\hline Zoo metacognitive monitoring & 0.00 & 0.00 & 0.03 & .98 & .00 \\
\hline Zoo bias index & 0.83 & 0.56 & 3.92 & $<.001$ & .10 \\
\hline Zoo absolute accuracy index & 0.35 & 0.11 & 0.88 & .38 & .02 \\
\hline \multicolumn{6}{|c|}{$F(7,167)=4.20, p=<.001, R^{2}=.15$} \\
\hline
\end{tabular}

Note $-{ }^{1}$ Bias index for the metamemory task only includes retrospective judgements (and not prospective judgements) because the New-Items were administered during the recall phase only. 


\section{Table S12}

All Hierarchical Regression Results for Metamemory Absolute Accuracy Index ${ }^{1}$ of the MixedItems Picture-Pair Set

\begin{tabular}{|c|c|c|c|c|c|}
\hline \multirow[t]{2}{*}{ Model Summary } & \multicolumn{5}{|c|}{ Parameter Estimates } \\
\hline & B & $\beta$ & $t$ & $p$ & $\delta$ \\
\hline \multicolumn{6}{|l|}{ Block 1} \\
\hline Intercept & 0.58 & 0.00 & 2.72 & .01 & \\
\hline Age & -0.02 & -0.07 & -0.89 & .37 & .02 \\
\hline Gender (female) & -0.02 & -0.07 & -0.90 & .37 & .02 \\
\hline \multicolumn{6}{|c|}{$F(2,173)=0.69, p=.50, R^{2}=.01$} \\
\hline \multicolumn{6}{|l|}{ Block 2} \\
\hline Intercept & 0.70 & 0.00 & 1.79 & .07 & \\
\hline Age & -0.01 & -0.03 & -0.43 & .67 & .01 \\
\hline Gender (female) & -0.01 & -0.06 & -0.82 & .41 & .01 \\
\hline Zoo accuracy & 0.08 & 0.04 & 0.23 & .82 & .00 \\
\hline Zoo metacognitive control & -0.02 & -0.09 & -0.99 & .32 & .02 \\
\hline Zoo metacognitive monitoring & -0.05 & -0.19 & -2.46 & .01 & .04 \\
\hline Zoo bias index & 0.14 & 0.14 & 0.95 & .34 & .02 \\
\hline Zoo absolute accuracy index & 0.19 & 0.09 & 0.68 & .50 & .01 \\
\hline \multicolumn{6}{|c|}{$F(7,167)=2.23, p=.03, R^{2}=.09$} \\
\hline
\end{tabular}

Note $-{ }^{1}$ Absolute Accuracy index for the metamemory task only includes retrospective judgements (and not prospective judgements) because the New-Items were administered during the recall phase only. 


\section{Table S13}

All Hierarchical Regression Results for Metamemory Accuracy of the New-Items Picture-Pair

Set

\begin{tabular}{|c|c|c|c|c|c|}
\hline \multirow[t]{2}{*}{ Model Summary } & \multicolumn{5}{|c|}{ Parameter Estimates } \\
\hline & B & $\beta$ & $t$ & $p$ & $\Delta$ \\
\hline \multicolumn{6}{|l|}{ Block 1} \\
\hline Intercept & 0.64 & 0.00 & 2.30 & .02 & \\
\hline Age & 0.02 & 0.04 & 0.51 & .61 & .01 \\
\hline Gender (female) & 0.04 & 0.12 & 1.53 & .13 & .04 \\
\hline \multicolumn{6}{|c|}{$F(2,173)=1.21, p=.30, R^{2}=.01$} \\
\hline \multicolumn{6}{|l|}{ Block 2} \\
\hline Intercept & 0.92 & 0.00 & 1.76 & .08 & \\
\hline Age & 0.01 & 0.03 & 0.44 & .66 & .01 \\
\hline Gender (female) & 0.04 & 0.11 & 1.45 & .15 & .03 \\
\hline Zoo accuracy & -0.65 & -0.23 & -1.34 & .18 & .03 \\
\hline Zoo metacognitive control & 0.02 & 0.08 & 0.89 & .37 & .02 \\
\hline Zoo metacognitive monitoring & 0.06 & 0.15 & 1.92 & .06 & .05 \\
\hline Zoo bias index & -0.32 & -0.25 & -1.66 & .10 & .04 \\
\hline Zoo absolute accuracy index & -0.33 & -0.12 & -0.90 & .37 & .02 \\
\hline \multicolumn{6}{|c|}{$F(7,167)=1.82, p=.09, R^{2}=.07$} \\
\hline
\end{tabular}




\section{Table S14}

All Hierarchical Regression Results for Metamemory Bias Index of the New-Items Picture-Pair

Set

\begin{tabular}{|c|c|c|c|c|c|}
\hline \multirow[t]{2}{*}{ Model Summary } & \multicolumn{5}{|c|}{ Parameter Estimates } \\
\hline & B & $\beta$ & $t$ & $p$ & $\delta$ \\
\hline \multicolumn{6}{|l|}{ Block 1} \\
\hline Intercept & -0.09 & 0.00 & -0.24 & .81 & \\
\hline Age & 0.01 & 0.01 & 0.17 & .87 & .01 \\
\hline Gender (female) & -0.06 & -0.15 & -1.97 & .05 & .06 \\
\hline \multicolumn{6}{|c|}{$F(2,173)=2.08, p=.13, R^{2}=.02$} \\
\hline \multicolumn{6}{|l|}{ Block 2} \\
\hline Intercept & -0.94 & 0.00 & -1.35 & .18 & \\
\hline Age & -0.01 & -0.02 & -0.23 & .82 & .01 \\
\hline Gender (female) & -0.06 & -0.15 & -1.96 & .05 & .06 \\
\hline Zoo accuracy & 1.25 & 0.33 & 1.93 & .06 & .06 \\
\hline Zoo metacognitive control & 0.00 & 0.01 & 0.08 & .94 & .00 \\
\hline Zoo metacognitive monitoring & -0.01 & -0.03 & -0.38 & .71 & .01 \\
\hline Zoo bias index & 0.60 & 0.34 & 2.30 & .02 & .07 \\
\hline Zoo absolute accuracy index & 0.30 & 0.08 & 0.60 & .55 & .02 \\
\hline \multicolumn{6}{|c|}{$F(7,167)=2.12, p=.04, R^{2}=.08$} \\
\hline
\end{tabular}




\section{Table S15}

All Hierarchical Regression Results for Metamemory Absolute Accuracy Index of the New-Items Picture-Pair Set

\begin{tabular}{|c|c|c|c|c|c|}
\hline \multirow[t]{2}{*}{ Model Summary } & \multicolumn{5}{|c|}{ Parameter Estimates } \\
\hline & B & $\beta$ & $t$ & $p$ & $\delta$ \\
\hline \multicolumn{6}{|l|}{ Block 1} \\
\hline Intercept & 0.68 & 0.00 & 2.17 & .03 & \\
\hline Age & -0.04 & -0.09 & -1.21 & .23 & .03 \\
\hline Gender (female) & -0.03 & -0.09 & -1.11 & .27 & .03 \\
\hline \multicolumn{6}{|c|}{$F(2,173)=1.16, p=.32, R^{2}=.01$} \\
\hline \multicolumn{6}{|l|}{ Block 2} \\
\hline Intercept & 0.72 & 0.00 & 1.27 & .21 & \\
\hline Age & -0.02 & -0.05 & -0.64 & .52 & .02 \\
\hline Gender (female) & -0.03 & -0.08 & -1.08 & .28 & .03 \\
\hline Zoo accuracy & 0.29 & 0.09 & 0.54 & .59 & .01 \\
\hline Zoo metacognitive control & -0.05 & -0.16 & -1.71 & .09 & .04 \\
\hline Zoo metacognitive monitoring & -0.08 & -0.21 & -2.68 & .01 & .07 \\
\hline Zoo bias index & 0.26 & 0.18 & 1.22 & .22 & .03 \\
\hline Zoo absolute accuracy index & 0.48 & 0.15 & 1.18 & .24 & .03 \\
\hline \multicolumn{6}{|c|}{$F(7,167)=3.31, p=.003, R^{2}=.12$} \\
\hline
\end{tabular}

